\title{
Discursos, performatividades e padrões visuais no cinema: reflexões sobre as representações de gênero, o mercado cinematográfico e o cinema de mulheres
}

\author{
Paula Alves \\ Escola Nacional de Ciências Estatísticas/IBGE \\ Paloma Coelho \\ Pontificia Universidade Católica de Minas Gerais
}

Resumo: Este artigo propõe reflexões acerca das representações do gênero no cinema, e de como o aumento da presença de mulheres no mercado cinematográfico pode favorecer a inclusão de novos olhares, perspectivas e experiências nos filmes. A baixa participação feminina em funções-chave da produção cinematográfica dificulta a ruptura dos padrões visuais do cinema hegemônico, que reafirmam e perpetuam as desigualdades de gênero. Considera-se, para tal reflexão, o cinema hegemônico, baseando-se nos dados de pesquisas referentes ao cinema brasileiro e estadunidense. Os dados apresentados apontam a importância da presença de mulheres na construção de novas linguagens, discursos e políticas no cinema.

Palavras-chave: Cinema; Representações de Gênero; Performatividades; Participação das mulheres no mercado audiovisual. 


\title{
Discursos, performatividades y patrones visuales en el cine: reflexiones sobre las representaciones de género, el mercado cinematográfico y el cine de mujeres
}

Resumen: Este artículo propone reflexiones sobre las representaciones de género en el cine, y de cómo el aumento de la presencia de mujeres en el mercado cinematográfico puede favorecer la inclusión de nuevas miradas, perspectivas y experiencias en las películas. La baja participación femenina en funciones clave de la producción cinematográfica dificulta la ruptura de los patrones visuales del cine hegemónico, que reafirman y perpetúan las desigualdades de género. Se considera en esta reflexión el cine hegemónico, basándose en los datos de investigaciones referentes al cine brasileño y estadounidense. Los datos presentados demuestran la importancia de la presencia de mujeres en la construcción de nuevos lenguajes, discursos y políticas en el cine.

Palabras clave: Cine; Representaciones de género; Performatividades, Participación de las mujeres en el mercado audiovisual.

\section{Speeches, performativities and visual patterns in the movies: reflections on gender representations, the film market and women film}

\begin{abstract}
This paper proposes reflections concerning the gender representations in film, and how the increased presence of women in the film market may favor the inclusion of new views, perspectives and experiences in the movies. The low female participation in key functions of film production makes it difficult to break the visual patterns of the hegemonic cinema, which reaffirm and perpetuate gender inequalities. It is considered, for this reflection, the hegemonic cinema, based on survey data regarding the Brazilian and the North American cinema. The data presented demonstrate the importance of the women's presence on building new languages, speeches and policies in cinema.

Keywords: Film; Gender Representations; Performativities; Women in the audiovisual labour market.
\end{abstract}




\section{Introdução}

O presente artigo aborda as relações entre gênero e cinema a partir de três perspectivas: em um primeiro momento, discute-se a maneira como as mulheres são retratadas no cinema hegemônico, e como os padrões visuais cristalizados pela narrativa clássica dificultam a emergência de outras representações de gênero, bem como a pluralidade de experiências, de olhares e de identidades. Em seguida, trata-se da participação das mulheres no cinema a partir de pesquisas realizadas sobre o mercado cinematográfico nos Estados Unidos e no Brasil. Por último, propõem-se uma reflexão sobre a ideia de "olhar feminino" no cinema, em uma tentativa de problematizar o conceito e desconstruir visões essencialistas sobre o tema.

O gênero, como uma categoria que se constitui continuamente nas relações sociais, tem no cinema um de seus veículos de (re)significação e de (re)elaboração de sentidos. Se pensado desde a perspectiva de Teresa de Lauretis (1984), o cinema seria um aparato de construção do gênero, ou uma "tecnologia do gênero", que consistiria, ao mesmo tempo, em produto e processo de sua representação. Aprimorando a concepção de Foucault sobre a "tecnologia sexual", as "tecnologias de gênero", das quais o cinema faz parte, corresponderiam aos discursos e às práticas institucionalizadas ou presentes na vida cotidiana. Desse modo, o cinema produziria representações de gênero, ao mesmo tempo em que essas representações seriam interpretadas e reconstruídas subjetivamente pelo espectador.

Assim como Linda Williams (2012) discute o cinema como um instrumento de educação sexual pelo fato de exibir e falar do sexo, convém pensar em uma espécie de educação visual empreendida pelas produções cinematográficas com respeito ao gênero. E isso inclui tanto a linguagem cinematográfica - enquadramento, montagem, discursos, contradiscursos, zonas de silêncio -, como a mise-en-scène - o olhar cinematográfico, $\mathrm{o}$ protagonismo, a constituição e disposição dos corpos no universo (extra)diegético. Se o gênero constitui e, simultaneamente, é constituído pelo cinema, tanto as performatividades, como os discursos de gênero que o cinema elabora, são resultado de um investimento imagético nos corpos que, consequentemente, originam concepções sobre o desejo e a sexualidade.

Também se pode pensar nas relações de poder a partir de duas perspectivas: as que são instituídas no universo diegético (o espaço fictício da narrativa) ${ }^{1}$; e as hierarquias produzidas sob o efeito de discursos que, quando reconfiguram as referências e os códigos simbólicos, contribuem para uma redefinição das posições dos sujeitos na estrutura social. Se o gênero pode ser definido como performativo, podemos pensar que as representações de gênero no cinema seriam duplamente performáticas. Ou que os corpos dos atores de ficção e/ou personagens reais de documentários (desenhos de corpos em animações, e quaisquer outras representações de corpos humanos) estariam duplamente "performando".

${ }^{1}$ Chamamos de diégèse ou "mundo da diégèse" o lugar ou a dimensão (o universo espaço-temporal) onde se passa a narrativa do filme, é o "mundo do filme", onde vivem as personagens e se desenvolvem as ações do filme. 


\section{Representação das mulheres no cinema hegemônico}

Para Judith Butler (2014), se a linguagem atua sobre nós antes de começarmos a atuar, e continua atuando no mesmo momento em que atuamos, temos que pensar na performatividade de gênero primeiro como uma "atribuição de gênero". Somos nomeados e nos atribuem um gênero sem mesmo entendermos sobre como as normas de gênero atuam sobre nós e nos formatam. Em outros termos, as regulações de gênero são anteriores aos indivíduos, já que elas constituem sujeitos "gendrados" em meio a expectativas sociais que orientam as referências identitárias desses sujeitos, ainda que o processo de performatividade compreenda não só a capacidade de reproduzir essas normas, como também de rompê-las.

E essas rupturas nas normas de fato podem acontecer, e acontecem, na performatividade de gênero. Isso porque a operacionalidade do gênero consiste na efetivação das normas que o regulam, isto é, depende da suscetibilidade dos indivíduos, que é anterior a sua capacidade de escolha, o que não anula, entretanto, a sua agência. A constituição do gênero envolve certa vulnerabilidade perante as normas, de maneira que qualquer ato discursivo seja precedido da sujeição dos indivíduos à linguagem (BUTLER, 2014).

Se os papéis de gênero são socialmente definidos e, como Judith Butler diz, nós os desempenhamos antes de nos darmos conta, no cinema esses papéis são exacerbados. Ou seja, se socialmente "performamos" características de feminino e masculino, no cinema esses estereótipos são intensificados. O cinema clássico narrativo (o cinema de Hollywood - hegemônico em todo o mundo) constrói suas personagens baseadas em rótulos e estereótipos, ou seja, em características padronizadas esperadas de cada grupo social: masculinidades e feminilidades, características e padrões de comportamento para os mocinhos, os bandidos, os heróis que, muitas vezes, atores e atrizes já possuem, mas que são especialmente "exagerados" pelas lentes do cinema.

O padrão de beleza instituído pelo cinema hollywoodiano, por meio do investimento na imagem do star system ${ }^{2}$, que passa a ditar referências de moda, de comportamentos e de estilos de vida, é um exemplo de como o cinema exacerba a imagem das atrizes através da maquiagem, da iluminação, dos enquadramentos; ou a construção da coragem ou força dos heróis, para além dos músculos definidos dos atores, em cenas de ação, luta e perigo. No cinema, mocinhas são sempre lindas, heróis são sempre corajosos e fortes - o que se espera então para as mulheres e homens na sociedade? O que se espera de atrizes e atores para que eles continuem sendo chamados a atuar em filmes? Por que a carreira de atrizes fora dos padrões de beleza e idade é mais difícil? Porque o cinema hegemônico estigmatiza as pessoas (reais ou fictícias). E como grande parte do público do cinema hegemônico está acostumada com os padrões de comportamento esperados para corpos masculinos e femininos, tanto quanto com a linguagem cinematográfica, esses códigos geralmente não são percebidos, e as performatividades de gênero do cinema, consequentemente, passam a ser reproduzidas na vida social.

\footnotetext{
${ }^{2}$ O fenômeno "star system" surge nos anos 1920 e nasce da concorrência entre os grandes estúdios estadunidenses e da constatação de que eram os nomes do elenco dos filmes que atraíam a plateia. É o sistema de "fabricação" e promoção das estrelas no cinema clássico de Hollywood.
} 
O cinema clássico narrativo reproduziu representações do patriarcado, das relações familiares, da sexualidade, criou o star system e o sexy symbol 3 e projetou a "objetificação"4 da mulher. O star system, por sua vez, determinou os padrões de beleza seguidos até hoje pela TV, publicidade e mídia em geral. O cinema padronizou personagens como o "herói”, o "bandido" e a "mocinha", e criou rótulos para pessoas e comportamentos, de acordo com os costumes de cada época em que foi produzido.

Laura Mulvey (1983) demonstra como o cinema clássico é dominado por uma lógica masculina do olhar, em que a mulher é colocada como objeto de desejo e de contemplação. A mulher seria concebida como o significante do outro masculino, na qual o homem projetaria suas fantasias e obsessões, colocando-a em uma posição de portadora e não produtora de significado, o que seria, para a autora, o reflexo da cultura patriarcal. Para Mulvey, a especificidade do cinema seria o prazer visual e, se tratando de um mundo marcado pela desigualdade sexual, o olhar cinematográfico estaria organizado por uma lógica do ativo/masculino e do passivo/feminino. $\mathrm{O}$ espectador de qualquer sexo, assim, teria uma relação voyeurística ${ }^{5}$ com a imagem da mulher na tela, pois os atores também atraíam audiência, mas, as atrizes eram adoradas por ambos os sexos.

O desenvolvimento do cinema como indústria está nitidamente ligado à beleza da estrela feminina. Começou-se a utilizar a luz difusa e lentes desenvolvidas especialmente para as atrizes e surge o close up ${ }^{6}$, que estagnava o movimento do filme desenvolvido pela montagem a fim de enfatizar a imagem da estrela como espetáculo à parte. A fascinação que a estrela exercia confundiase com a própria fascinação do cinema. Ela era a marca do potencial sedutor do cinema e, por consequência, do espetáculo da mercadoria (MULVEY, 1983).

Enquanto o star system transformava as imagens de suas estrelas em emblemas de sexualidade, o cinema clássico narrativo de Hollywood se expandia influenciando os cinemas nacionais de todos os países. Assim, o cinema estadunidense dominou o entretenimento no mundo e a imagem da mulher no cinema passou a ser ícone de sexualidade. O corpo feminino foi rapidamente transformado em objeto de consumo. Diante da sua função exibicionista, a objetificação sexual da mulher se opõe ao personagem masculino como sujeito da história, responsável por conduzir o desenvolvimento dos acontecimentos. O homem detém o poder porque é o dono do olhar, é ele quem controla o filme em seu universo diegético e extradiegético (o olhar do espectador que se identifica com o protagonista masculino).

A figura da mulher opera como objeto erótico tanto para os personagens na tela, quanto para o espectador, que pode indiretamente possuí-la, e o cinema cria a interação entre ambos os olhares. Nesse sentido, Mulvey critica o fato desse cinema transformar a mulher no elemento fundamental para o espetáculo do filme, e não para o desenvolvimento da história; ela mais bem representaria a imagem contemplativa que paralisa o fluxo da narrativa. Isso contribui para que a sua presença em si mesma não seja tão relevante quanto o que ela pode provocar no personagem masculino - sentimentos, sensações, preocupações que é o que move a sua ação (MULVEY, 1983).

${ }_{3}^{3}$ Símbolo de sensualidade e sexualidade. O termo passou a ser usado especialmente a partir dos anos 1950, referindo-se a astros e estrelas do cinema.

4 Exposição do corpo feminino como objeto de desejo e de consumo.

5 Voyeurismo é o ato de observar prazerosamente alguém sem que o mesmo tenha conhecimento disto.

${ }^{6}$ Plano muito próximo, que enquadra somente o rosto da atriz. 
O chamado cinema clássico narrativo ou cinema clássico americano é marcado por construções de artimanhas de envolvimento do espectador: o star system, o bem contra o mal, o mocinho contra o bandido, uma história de amor, "cortes escondidos" e mudanças clássicas de planos, ou seja, nada de chamar a atenção para as técnicas cinematográficas, mas, ao contrário, manter o espectador tão envolvido e concentrado na trama que ele seja capaz de "esquecer" momentaneamente que assiste a um filme. Nesse cinema, a representação da mulher sempre foi usada como uma dessas artimanhas de envolvimento e atração do público tanto masculino quanto feminino: as estrelas.

Mulvey (1983) baseou-se na psicanálise para demonstrar que a forma do cinema foi estruturada segundo o inconsciente da sociedade patriarcal. Segundo ela o fascínio pelo cinema é resultado de sua manipulação do prazer visual e sua codificação do erótico dentro da linguagem patriarcal dominante. O prazer em olhar outra pessoa como objeto é realizado pelo cinema na medida em que coloca seu espectador numa sala escura de onde lhe é permitido espiar: a escopofilia. Outra forma de prazer também é oferecida pelo cinema ao espectador que se identifica e se reconhece no filme: o narcisismo. A escopofilia define-se num prazer visual entendido como um prazer erótico do indivíduo em exibir-se, como também, na situação inversa, em observar outra pessoa ou imagens de outros corpos (NEVES, 2007). Mulvey assume a escopofilia como uma das possibilidades do prazer visual dentro do qual acontece um transporte dessa observação pessoal para o outro. Ela considera que o cinema satisfaz um desejo primordial no que concerne ao prazer de olhar, mas também vai mais além, desenvolvendo a escopofilia no seu aspecto narcísico na fascinação pela semelhança e reconhecimento (NEVES, 2007).

Numa sociedade dominada pelo homem, é o prazer visual masculino que se procura satisfazer, oferecendo ao espectador o reconhecimento no protagonista masculino e o prazer em observar a mulher como objeto duplamente erótico: para os personagens masculinos do filme e para o espectador. A proposta de Mulvey é, então, a construção de um cinema alternativo. Segundo ela:

\footnotetext{
Não importa o quanto irônico e autoconsciente seja o cinema de Hollywood, pois sempre se restringirá a uma mise-en-scène formal que reflete uma concepção ideológica dominante do cinema. O cinema alternativo por outro lado cria um espaço para o aparecimento de um outro cinema, radical, tanto num sentido político, quanto estético e que desafia os preceitos básicos do cinema dominante. Não escrevo isso no sentido de uma rejeição moralista desse cinema, e sim para chamar a atenção para o modo como as preocupações formais desse cinema refletem as obsessões psíquicas da sociedade que o produziu, e, mais além, para ressaltar o fato de que o cinema alternativo deve começar especificamente pela reação contra essas obsessões e premissas (MULVEY, 1983: 439).
}

Esse cinema alternativo teria como função a destruição do prazer visual, a negação do controle do olhar masculino a favor da elaboração de uma nova linguagem do desejo. Para a autora, o caráter ilusionista do cinema deve ser desafiado, já que as estratégias do dispositivo cinematográfico tendem a ocultar o seu caráter discursivo e a se oferecerem ao espectador como uma realidade sem mediação.

No que diz respeito à linguagem cinematográfica e as suas estratégias discursivas, Ismail Xavier (2008) esboça dois percursos possíveis na produção de um filme: o da "opacidade" e o da "transparência". De acordo com o autor, 
quando o dispositivo cinematográfico, ou seja, todo o aparato tecnológico e econômico que envolve os aspectos de sua montagem, é ocultado do espectador para que a ilusão e a impressão de "realidade" sejam acentuadas, tem-se o efeito da transparência. Quando, ao contrário, o filme expõe os aspectos de sua construção, ou o dispositivo, propiciando ao espectador maior distanciamento e posicionamento crítico, opera-se o efeito da opacidade.

O efeito da transparência, convencionalmente utilizado pela narrativa clássica, fornece a impressão de contato direto com o universo retratado na tela, acentuando a identificação do espectador e dificultando o seu distanciamento. É esse efeito que Mulvey julga ser necessário destruir para que o filme não obscureça “o realismo, o óbvio e a verdade". Nessa lógica, se o aparato cinematográfico oculta a presença da câmera e os efeitos de construção fílmica, acentuando a verossimilhança do que é mostrado, a imagem da mulher como fetiche, como objeto erótico e como ser passivo jamais poderia ser superada, mas naturalizada e reafirmada diante da tela.

É esse caráter ilusório, na concepção de Mulvey, que o cinema alternativo teria que negar, juntamente com a mudança na ênfase do olhar, "já que é o olhar e a possibilidade de variá-lo e de expô-lo que definem o cinema” (MULVEY, 1983: 452). Uma nova linguagem do desejo implicaria, assim, na destruição desse olhar escopofílico, voyeurista, típico do prazer tradicional cinematográfico para convocar o espectador a um trabalho ativo diante do filme e na negação das premissas ancoradas em um sistema patriarcal.

Lauretis (1984) também discute a figura da mulher7 no cinema. Retomando a noção de Barthes da "civilização da imagem", ela afirma que o cinema consiste em uma máquina de representação que produz imagens, mas também reproduz a mulher como imagem. Suas reflexões apontam para a dimensão política da expressão estética, de maneira que um filme é definido não apenas pelo que ele diz, mas pelo que é mostrado e pela forma como é mostrado. A mulher no cinema seria retratada como a origem do desejo masculino, como objeto e signo da sua cultura e da sua criatividade, e ocuparia o espaço da não coerência, do vazio de significado, que a impediria de reivindicar a posição de sujeito da representação.

A mulher como imagem transformada em espetáculo, em objeto a ser observado/contemplado, não é uma criação do cinema, mas está presente na nossa cultura, que concebe o corpo feminino como o lócus da sensualidade, do prazer visual e da sedução do olhar. Para Lauretis, o problema consiste na noção da diferença sexual e, assim, ela questiona como o cinema poderia pensar as mulheres fora da dicotomia homem-mulher, para pensar e falar como uma mulher, ou como torná-la sujeito em uma cultura que a objetifica, a exclui e a oprime.

Segundo a autora, um novo cinema seria necessário, mas, criticando a posição de Laura Mulvey, ela não considera necessária a destruição do prazer visual, e sim propõe a construção de outro quadro de referência e outras condições de visibilidade para um diferente sujeito social:

(...) O que vejo agora é que é possível para o cinema de mulheres responder ao apelo de uma 'nova linguagem do desejo'. Quero ver se é possível, mesmo sem a prescrição estóica e brutal da autodisciplina, e sem a destruição do prazer visual, que parecia

7 O termo "mulher" é aqui empregado de acordo com a discussão de Mulvey e Lauretis, considerando que nesse momento o debate em torno do gênero ainda não questionava o uso da categoria "mulher" como um sujeito essencial e naturalizado. A compreensão da diferença não apenas entre os gêneros, mas também no interior de cada categoria, e da incorporação da ideia de interseccionalidade e das experiências emergem em outro contexto no debate feminista. 
inevitável no momento. Mas se o projeto do cinema feminista - construir os termos de referência de outra medida do desejo e as condições de visibilidade para um sujeito social diferente - parece agora mais possível e, de fato, real, é em grande parte devido ao trabalho produzido em resposta à autodisciplina e ao conhecimento gerado a partir da prática do feminismo e do filme (LAURETIS, 1984: 155).

A proposta de Lauretis para o que ela chama de "cinema de mulheres" é criar outras formas de visão capazes de gerar a identificação com as espectadoras, que não se reconheceriam nas imagens retratadas pelo cinema clássico. Uma nova linguagem do desejo que desloque a figura da mulher como objeto para tomá-la como sujeito da ação. Além disso, criticando mais uma vez a ideia de Mulvey, Lauretis não defende a negação do ilusionismo do cinema, já que ele lhe é inerente. Todo filme, por mais "realista" que se pretenda ser, não conseguiria se desvencilhar de seu caráter ilusório, pelo fato de nenhuma produção cinematográfica ser capaz de apreender o real.

A autora argumenta, ainda, que o cinema surgiu em função do prazer visual e, por isso, o "cinema de mulheres" não deveria tentar destruí-lo, mas problematizar seus termos na própria experiência cinematográfica. E, ao contrário do que defendia Mulvey, em sua crítica ao cinema hollywoodiano, Lauretis afirma que o cinema feminista não deveria evitar, mas incorporar o cinema mainstream porque uma nova configuração da linguagem cinematográfica se daria pela libertação dos desejos e das fantasias femininas, o que só seria possível pela via do entretenimento (LAURETIS, 1984; 1987). Essa perspectiva que se propõe a lançar mão de aspectos do cinema clássico não implica, porém, em uma total adesão aos seus preceitos, já que essa nova proposição da produção cinematográfica orientada por uma consciência feminista ainda permanece como uma maneira alternativa de fazer cinema. Ou seja, apesar da apropriação de alguns elementos, esse "cinema de mulheres" ainda opera pela lógica de ruptura com a máquina ideológica do cinema hegemônico.

A noção de Lauretis da criação por parte do cinema de condições de visibilidade para um novo sujeito social implica, ainda, na necessidade de se evitar a supressão das diferenças. Para ela, o cinema de vanguarda deveria ser capaz de retratar a "diferença diferentemente", ou seja, não abordar a figura feminina como "a mulher", por meio de uma imagem fixa, mas admitindo - e dando espaço para - a heterogeneidade. Nas palavras da autora, o filme "pode se dirigir a mim como uma mulher, não se referindo ou me apontando como Mulher" (LAURETIS, 1984: 142). O que caracterizaria o cinema feminista seria o fato de ele ser direcionado ao público feminino, independentemente do seu gênero. Não bastaria, portanto, que ele fosse feito por mulheres, teria que ser construído para as mulheres.

Desse modo, o "cinema de mulheres" teria que gerar a identificação com a espectadora, mas também lhe proporcionar um lugar nele, incorporando as contradições e singularidades pessoais e políticas presentes nas mulheres dentro e fora da tela. Isso porque a construção social do gênero, da subjetividade e da representação da experiência ocorre tanto em interseção com a raça e com a classe, quanto na - e por meio da - linguagem e cultura. Baseando-se na semiótica, Lauretis compreende o gênero e a diferença sexual como categorias instituídas no nível semântico e linguístico. Para ela, o gênero deveria ser entendido não como uma diferença biológica, mas sim semiótica, produto da construção de significados, que são indissociáveis da experiência. Superar a ideia de diferença sexual, assim, seria, tanto no cinema, quanto na 
linguagem e na cultura, negar-se a tomá-la ou aceitá-la como verdadeira (LAURETIS, 1984).

O cinema clássico, por trás da representação do corpo feminino como objeto de consumo e da utilização de estereótipos, reafirma a distinção de papéis de homens e mulheres, não só refletindo a sociedade como influenciando-a, num círculo vicioso. Dessa forma, não só a representação da mulher no cinema majoritariamente foi a partir de valores masculinos, como os próprios meios de comunicação mantinham com sua representação depreciada a sua posição inferior na sociedade. Por isso, a modificação da imagem da mulher na mídia sempre teve imensa importância para o movimento feminista, não apenas como seu reflexo, mas, como seu aliado no sentido de mudar a imagem inferiorizada da mulher. A representação da mulher no cinema quase sempre acompanhou as mudanças na sociedade. A partir da década de 1970, se podem notar mudanças na representação da mulher nos filmes produzidos, especialmente em filmes dirigidos por mulheres, como reflexos das mudanças na condição feminina.

Segundo Higonnet (1993), somente nas últimas décadas do século XX, as mulheres começam a afrontar as contradições entre as formas como são vistas pelos outros e as formas como elas mesmas se veem. Elas precisaram enfrentar algumas questões nessa representação de si mesmas. Uma delas era o corpo, entre o desejo de celebrar sua beleza e o medo de se representar como objeto sexual, algumas artistas preferiram não representar o corpo diretamente. Outras optaram por produzir imagens eróticas substituindo o nu feminino pelo masculino. Outra questão era se as mulheres deveriam adotar como os homens o culto ao herói. Era difícil repensar uma história da imagem escapando dos conceitos tradicionais e fazer produções visuais sem seguir esses conceitos. As mulheres utilizaram a diversidade para resolver os problemas de representar-se a si mesmas, apropriando-se da imagem clássica e modificando seu sentido de forma irreverente e/ou crítica, realizando uma produção artística com novas linguagens, formas de expressão e formatos inovadores. Para Higonnet "para criar novas imagens de si mesmas, as mulheres tiveram que aprender a adotar e cultivar novas atitudes ante a si mesmas, ante ao seu corpo e ante ao lugar que ocupam na sociedade" (1993: 432).

\section{Participação das mulheres no mercado de trabalho cinematográfico}

Nos EUA hoje em dia, as mulheres podem ser encontradas em posições chave na indústria do cinema. Alguns dos maiores estúdios são dirigidos por mulheres, diretoras estão fazendo filmes de grandes orçamentos, e o número de mulheres produtoras é cada vez maior. No entanto, executivos do film business $^{8}$, como Howard Rodman (diretor da Divisão de Roteiro da Escola de Cinema e Televisão de USC9) e Barbara Corday (primeira mulher presidente da Columbia Pictures ${ }^{10}$ ) acham que estúdios de cinema são tradicionalmente uma cultura masculina e que os homens em altos cargos não se sentem muito confortáveis trabalhando com mulheres (apud TREMILLS, 2005).

${ }^{8}$ Mercado/indústria do cinema.

9 University of Southern Califórnia.

${ }^{10}$ Uma das maiores empresas de produção e distribuição de cinema dos EUA e do mundo. 
Segundo Martha Lauzen, responsável pela pesquisa anual sobre as mulheres empregadas nos filmes de grande bilheteria de Hollywood, The Celluloid Ceiling, e professora da Escola de Teatro, Televisão e Cinema da Universidade Estadual de San Diego, nos filmes com produtores executivos apenas homens, as mulheres tem menor representação nas equipes, enquanto que nos filmes com pelo menos uma mulher entre os produtores executivos, as mulheres têm maior chance de desempenhar funções-chave, como a produção, a direção, o roteirista, a edição e a fotografia.

De acordo com esta pesquisa, em 2006, as mulheres representavam $15 \%$ entre todos os diretores, produtores executivos, produtores, roteiristas, fotógrafos e editores trabalhando nos 250 filmes de maior bilheteria nos EUA. Essa pesquisa analisou as funções de 2.718 empregados nos 250 filmes de maior bilheteria de 2006, que somados tiveram bilheteria doméstica (apenas dentro dos EUA) de aproximadamente 8,9 bilhões de dólares. Entre os filmes lançados em 2006, 22\% não empregaram nenhuma mulher nas funções de direção, produção executiva, produção, roteiro, fotografia ou edição. Nenhum filme deixou de empregar um homem em pelo menos uma dessas funções. A tabela 1 apresenta a evolução dos resultados dessa pesquisa, que é realizada anualmente.

Tabela 1

Distribuição percentual de empregados em funções-chave, nos 250 filmes de maior bilheteria no mercado interno estadunidense, por sexo

\begin{tabular}{l|c|c|c|c|c|c}
\hline Sexo | Ano & $\mathbf{1 9 9 8}$ & $\mathbf{1 9 9 9}$ & $\mathbf{2 0 0 1}$ & $\mathbf{2 0 0 3}$ & $\mathbf{2 0 0 5}$ & $\mathbf{2 0 0 6}$ \\
\hline Homens & 83 & 85 & 81 & 83 & 83 & 85 \\
\hline Mulheres & 17 & 15 & 19 & 17 & 17 & 15 \\
\hline
\end{tabular}

Mesmo com as mulheres ocupando posições na direção dos estúdios, o número de mulheres desempenhando funções-chave nas equipes não cresceu. Segundo Tremills, alguns executivos argumentam que a indústria do cinema é uma indústria como outra qualquer nos EUA e que os donos dos estúdios determinam os filmes que vão ser produzidos e o quanto se investirá neles, não importa o quanto um roteiro seja bom, o importante é o quanto os donos dos estúdios acreditam que o filme dará lucro. Os donos dos estúdios ainda são predominantemente homens (TREMILLS, 2005, p. 45).

Tremills (2005, p. 45) acredita que "ao contrário da sua imagem de pensamento criativo, Hollywood adora categorizar as pessoas - homens e mulheres - em rótulos." Segundo ela, uma vez que um diretor tenha feito um filme de ação de sucesso, sempre lhe será oferecido um filme de ação. Quando um roteirista cria uma comédia romântica brilhante, ele nem tem a chance de pensar em tentar emplacar um roteiro de ficção científica. Esses rótulos se estendem aos estereótipos de gênero. Os donos dos estúdios ainda acreditam nas diferenças entre filmes masculinos e femininos. Ação e terror vendem para homens. Comédia romântica e drama vendem para mulheres. Segundo esses rótulos, filmes de homens fazem mais dinheiro. Filmes de mulheres são mais difíceis de vender, especialmente se a história tem protagonista feminina.

Se as "histórias de homens" são as que têm perspectivas de fazer dinheiro, o estereótipo se estende para as pessoas que são contratadas para escrever, dirigir, fotografar e editar o filme, segundo Howard Rodman (apud TREMILLS, 2005: 45). É um círculo vicioso: mulheres seriam apropriadas para fazerem 
filmes femininos; filmes femininos não fazem dinheiro; então as mulheres têm baixa participação entre roteiristas e diretores na indústria estadunidense.

O número de mulheres produtoras nos 250 filmes de maior bilheteria quase não apresentou crescimento, conforme se observa na tabela 2: em 1998 as mulheres representavam 24\% e em 2012, 25\%. Já entre as produtoras executivas e fotógrafas houve retrocesso. Entre os diretores, as mulheres mantiveram a marca dos 9\% em 1998 e 2012, no entanto, houve um retrocesso ao longo desse período, as mulheres representaram 7\% dos diretores em 2006, isso é menos do que o máximo atingido em 2000, $11 \%$.

Tabela 2

Mulheres em funções-chave nos 250 filmes de maior bilheteria no mercado interno estadunidense

\begin{tabular}{l|c|c|c|c}
\hline Funções | Ano & $\mathbf{1 9 9 8}$ & $\mathbf{2 0 0 0}$ & $\mathbf{2 0 0 6}$ & $\mathbf{2 0 1 2}$ \\
\hline Diretoras & $9 \%$ & $11 \%$ & $7 \%$ & $9 \%$ \\
\hline Roteiristas & $13 \%$ & $14 \%$ & $10 \%$ & $15 \%$ \\
\hline Produtoras executivas & $18 \%$ & $16 \%$ & $16 \%$ & $17 \%$ \\
\hline Produtoras & $24 \%$ & $24 \%$ & $20 \%$ & $25 \%$ \\
\hline Editoras & $20 \%$ & $19 \%$ & $21 \%$ & $20 \%$ \\
\hline Fotógrafas & $4 \%$ & $2 \%$ & $2 \%$ & $2 \%$ \\
\hline
\end{tabular}

Fonte: LAUZEN, 2013.

Outros resultados dessa pesquisa mostraram que considerando-se o gênero do filme, as mulheres estão mais propensas a trabalhar em documentários e comédias românticas e menos a trabalhar em ficção científica e filmes de terror. Em 2006, mulheres representaram 28\% dos indivíduos trabalhando em documentários, 25\% em comédias românticas, 23\% em comédias dramáticas ou tragicomédias, 19\% em dramas românticos, $16 \%$ em animações, $14 \%$ em dramas, $12 \%$ em comédias, ação e aventura, $10 \%$ em ficção científica e $5 \%$ em filmes de terror (LAUZEN, 2010).

Entre 2009 e 2011 foi realizada uma pesquisa sobre a participação das mulheres no cinema brasileiro para a qual foi elaborada uma base de dados contendo as seguintes informações sobre os filmes de longa-metragem finalizados/lançados entre os anos 1961 e 2010: título, nome do/a diretor/a, sexo do/a diretor/a, sexo do/a produtor/a, sexo do/a produtor/a executivo/a, sexo do/a roteirista, sexo do/a diretor/a de fotografia e/ou câmera, protagonista, diretor/a de arte, assistente de direção, diretor/a de produção, ano de finalização/lançamento, gênero do filme, temática do filme, e outras funções (ALVES, 2011). Foi considerada a classificação internacional de filme de longa-metragem, ou seja, foram considerados filmes com duração igual ou superior a 60 minutos, para que se pudesse fazer comparações em futuros estudos entre as características da cinematografia brasileira com a de outros países ${ }^{11}$.

\footnotetext{
${ }_{11}$ A Agência Nacional do Cinema - Ancine considera filme de longa-metragem aquele que tiver duração superior a 70 minutos. No entanto, internacionalmente, a definição de duração mínima para longa-metragem varia de país para país bem como entre os festivais de cinema internacionais. Alguns festivais de cinema seguem os critérios dos órgãos reguladores da atividade audiovisual de seus países, e outros as classificações mais comumente utilizadas internacionalmente. Por isso, para fins de comparação internacional, considerou-se nesse estudo filme de longametragem aquele com duração igual ou superior a 60 minutos. Essa classificação independe do formato de captação ou
} 
A produção de filmes de longa-metragem é dividida em vários processos e fases (desenvolvimento, pré-produção, captação, produção, pós-produção, finalização, lançamento). Por isso, para a definição de ano do filme considerouse o ano de lançamento para filmes lançados no circuito comercial ou em festivais; e o ano de finalização para filmes prontos, mas não lançados comercialmente. Os dados para elaboração desta base foram obtidos nos créditos, nas sinopses e sites oficiais dos filmes, em catálogos de festivais de cinema, numa pesquisa realizada pelo pesquisador Antonio Leão da Silva Neto, publicada em livro (Dicionário de filmes brasileiros: longa-metragem $-2^{a}$ edição revista e atualizada), nos portais Filme B, AdoroCinema e no Guia Kinoforum: festivais de cinema e vídeo 2011.

A partir dos dados desta pesquisa, constatamos que a presença das mulheres nas equipes dos filmes de longa-metragem produzidos entre os anos 1961 e 2010 no Brasil também é baixa. Verifica-se na tabela 3 que em todas as décadas a proporção de filmes dirigidos por mulheres aumentou significativamente ao longo do período estudado, no entanto, esta proporção é muito baixa. Nota-se que dos anos 1960 para os anos 1970, a participação percentual feminina na direção mais que dobrou. Entre os anos 1980 e 1990, o aumento foi de 2,47 vezes - o maior aumento no período estudado. Percebemos que as funções direção e roteiro em relação à participação feminina são semelhantes - 15,37\% dirigidos na última década, entre 2001 e 2010, e 13,78\% roteirizados.

Tabela 3

Proporção de mulheres em funções-chave nos filmes de longa-metragem, Brasil

\begin{tabular}{l|c|c|c|c|c}
\hline Funções $\mid$ Década & $\mathbf{1 9 6 1 - 1 9 7 0}$ & $\mathbf{1 9 7 1 - 1 9 8 0}$ & $\mathbf{1 9 8 1 - 1 9 9 0}$ & $\mathbf{1 9 9 1 - 2 0 0 0}$ & $\mathbf{2 0 0 1 - 2 0 1 0}$ \\
\hline Direção & 0,68 & 1,77 & 3,27 & 11,35 & 15,37 \\
\hline Roteiro & 0,68 & 2,43 & 3,60 & 9,51 & 13,78 \\
\hline Produção* & 0,68 & 2,77 & 4,17 & 13,50 & 23,71 \\
\hline Fotografia** $^{*}$ & 0,00 & 0,33 & 0,45 & 0,00 & 3,19 \\
\hline
\end{tabular}

* Produção inclui dados de produção, produção executiva e direção de produção.

${ }^{*}$ Fotografia inclui dados de direção de fotografia, fotografia e câmera.

Fonte: ALVES, 2011.

Percebe-se que em todas as décadas há mais filmes produzidos por mulheres do que roteirizados ou dirigidos. De toda forma, a baixa participação feminina nesta área - não chega a 24\% entre 2001 e 2010 - surpreende, especialmente nas últimas décadas, porque existe uma falsa impressão entre os profissionais do mercado audiovisual de que as mulheres teriam uma grande participação na produção cinematográfica. Comparando-se com as demais funções, a área onde a participação feminina é menor, em todas as décadas, é na fotografia, passando apenas um pouco de $3 \%$ na última década, assim como acontece no cinema estadunidense.

Segundo Dargis (2008), além do baixo número de mulheres diretoras e em funções-chave, as protagonistas femininas também estavam em baixa nos filmes dos grandes estúdios lançados no verão americano de 2008. Martha Lauzen afirma que as protagonistas mulheres do cinema hollywoodiano são 
majoritariamente jovens (20 a 30 anos), bonitas, não têm, muitas vezes, uma ocupação definida, suas buscas giram em torno do amor, casamento e família. Enquanto que os protagonistas homens variam mais de idade (de jovens a maduros, 30 a 50 anos), sempre tem profissão definida, estão em busca de grandes realizações, como salvar o mundo, resolver questões complexas, fazer justiça, etc. (LAUZEN, 2010).

O protagonismo pode ser interpretado como uma forma de quantificar a representação de homens e mulheres nos filmes. Isto é, quanto maior o número de filmes com protagonistas mulheres, maior a representação das mulheres pelo cinema, visto que o protagonista é aquele personagem que normalmente tem um objetivo, uma meta, é o líder de um grupo no alcance desta meta, é através do qual o filme é contado, ou seja, o filme privilegia o seu ponto de vista. A partir da tabela 4 verifica-se que em todas as décadas, no Brasil, o número de filmes protagonizados por mulheres é menor do que os protagonizados por homens e protagonizados por ambos, ou seja, homens e mulheres.

Tabela 4

Distribuição percentual de filmes de longa-metragem por sexo do protagonista, Brasil

\begin{tabular}{l|c|c|c}
\hline Sexo do Protagonista | Década & $\mathbf{1 9 9 1 - 2 0 0 0}$ & $\mathbf{2 0 0 1 - 2 0 1 0}$ & Total \\
\hline Homens & 63,50 & 56,33 & 58,00 \\
\hline Mulheres & 13,80 & 18,18 & 17,16 \\
\hline Ambos* & 15,03 & 22,96 & 21,11 \\
\hline sem informação & 7,67 & 2,53 & 3,73 \\
\hline
\end{tabular}

*Filmes protagonizados por homens e mulheres.

Fonte: ALVES, 2011.

Os filmes protagonizados por mulheres na última década representam apenas 18,18\%. Da mesma forma que na produção, a baixa participação feminina no protagonismo também surpreende, pois existe um falso discurso de que embora as mulheres estejam pouco representadas nas equipes, estariam em igualdade nas telas.

Não à toa, nos últimos anos o tema da presença feminina no cinema vem ganhando notoriedade. Festivais como Cannes e Berlin foram alvo de protestos de movimentos feministas pela ausência de filmes dirigidos por mulheres nas principais competições. No Oscar 2015, atrizes reclamaram da ausência de bons papéis para mulheres maduras - o que já havia sido apontado pelo crítico de cinema Serge Daney em 1997, bem como em diversas pesquisas como a da própria Martha Lauzen ou das Guerrilla Girls (2011) ${ }^{12}$. Em 2015, pela primeira vez o festival de Cannes teve como filme de abertura um trabalho dirigido por uma mulher, fato que virou notícia por sua raridade (La Tête Haute, da diretora francesa Emmanuelle Bercot). Por toda a história do cinema até bem pouco tempo, a presença de mulheres era exatamente isso, um fato raro, as mulheres que se aventuravam na direção cinematográfica eram exceções. Tanto quanto inusitado era uma mulher ganhar prêmios desempenhando esta função.

Apenas em 2010 um filme dirigido por uma mulher recebeu o prêmio máximo da academia americana, o Oscar de melhor filme (Guerra ao Terror, de Kathryn Bigelow) que, por sua vez, foi apontado como um filme nada 
"feminino", de acordo com a visão convencional da indústria cinematográfica, que classifica os gêneros e as temáticas dos filmes segundo estereótipos do que corresponderiam aos interesses e assuntos de homens e mulheres. No caso de Kathryn Bigelow, chama a atenção o fato de que na primeira e única vez em que um filme dirigido por uma mulher venceu a categoria de melhor filme pela academia de Hollywood, foi por um filme de guerra, com protagonistas homens e que, tradicionalmente, também é direcionado ao público majoritariamente masculino. Ou seja, o reconhecimento da diretora ocorreu em função de um filme cuja temática e abordagem é considerada pelas convenções do cinema clássico como "masculina" - o que suscita e nos faz voltar a uma questão polêmica introduzida anteriormente, a do cinema de mulheres e/ou cinema feminista. A grande discussão quando se fala em filmes de diretoras: o olhar feminino.

\section{As mulheres na direção cinematográfica e o "cinema de mulheres"}

Segundo Buet (1999), nas primeiras décadas do cinema, as mulheres estavam presentes principalmente como atrizes e assistentes. A presença de mulheres na direção cinematográfica era rara. Nos anos 1950, acontece uma descentralização das artes na Europa e surgem os festivais independentes de teatro, nos anos 1960 são criados centros culturais e cineclubes e, nos anos 1970, os festivais independentes de cinema. O número de diretoras aumenta nessa época com um cinema influenciado pelos movimentos sociais $\mathrm{e}$ feministas.

Segundo Ann Kaplan (1995), nos EUA e na Europa as mulheres encontraram espaço para fazer cinema especialmente no cinema independente experimental e documental, que questionavam formas e conteúdo, e por isso, estavam abertos aos questionamentos feministas. A exclusão da mulher até então na direção cinematográfica possibilitou que as cineastas se tornassem especialmente sensíveis à questão da forma e estilo, e impediu que seguissem cegamente as antigas convenções. Para muitas mulheres o cinema experimental representou uma liberação das representações ilusionistas, opressivas e artificiais do cinema hollywoodiano. As diretoras responderam à apropriação hollywoodiana da imagem feminina e começaram a explorar as possibilidades de se dar à mulher uma voz e um status enquanto sujeito.

Da mesma forma no Brasil, alguns autores afirmam que as mulheres estrearam em sua maioria na direção cinematográfica com filmes protagonizados também por mulheres e temas em que a feminilidade ou o corpo feminino é central (OTTONE, 2005; PESSOA, 1989). Segundo Pessoa (1989), quando as realizadoras começam a atuar, dentre os diversos temas explorados em filmes de documentário, destaca-se o da situação da mulher na cultura e na sociedade, enquanto entre as ficções, filmes polêmicos e ousados abordam a liberação sexual feminina e criticam o consumo da mulher como objeto erótico. Já Ottone (2005), considera que uma das marcas da chamada retomada do cinema brasileiro nos anos 1990 são os filmes autorais femininos.

Como vimos nos dados apresentados anteriormente, até os anos 1970 podemos dizer que o cinema era realizado praticamente por homens (mulheres na direção, roteiro e outras funções-chave eram exceções), desde uma perspectiva masculina. A partir, especialmente, dos anos 1970, e sob a influência 
de movimentos sociais, negros e feministas, as diretoras surgem no cenário audiovisual com filmes marcados por personagens femininas fortes, e temas que abordavam a situação da mulher na sociedade, no trabalho e nas relações afetivas, casamento, liberdade sexual, objetificação do corpo feminino, entre outros, numa busca por uma autorrepresentação, ou uma representação dos corpos femininos sob uma nova perspectiva.

$\mathrm{Na}$ pesquisa citada anteriormente, foram realizados testes estatísticos para verificar a associação entre o sexo do protagonista e as demais funções pesquisadas no cinema brasileiro. Foram encontrados indícios de que existe uma associação entre o sexo do protagonista e o sexo do diretor e do roteirista. Também se verificou que há evidências de associação entre o sexo do protagonista e o gênero do filme. Notou-se que as mulheres têm maior participação como protagonistas nos filmes de ficção do que nos documentários.

Os resultados dos testes fazem sentido teórico, uma vez que a direção e o roteiro são as funções que mais influenciam na escolha e construção dos protagonistas, ou melhor, são as funções responsáveis pela construção técnica e artística do filme e, consequentemente, pela construção das personagens, pelas escolhas das histórias a serem contadas pelo filme e de que maneiras serão contadas. Por isso, é esperado que exista associação entre o sexo dos diretores e roteiristas e dos protagonistas dos filmes, o que significa dizer que a presença de roteiristas e diretoras mulheres pode influenciar a escolha por realização de filmes com protagonistas também mulheres. Verificou-se também a associação entre o sexo das pessoas que desempenham funções-chave nos filmes e foram encontradas evidências de associação entre o sexo do diretor com o sexo do roteirista, do produtor e do fotógrafo; assim como entre o sexo do diretor e o gênero do filme. Ao contrário do protagonismo, as mulheres têm maior presença na direção cinematográfica nos filmes de documentário e não nos de ficção (ALVES, 2011).

Verificou-se que quando o gênero do filme é documentário a vantagem em favor do filme ser dirigido por uma mulher é 2,6 vezes maior do que nos filmes de ficção. Quando a roteirista do filme é mulher a vantagem em favor do filme ser dirigido também por uma mulher é cerca de 238 vezes maior do que nos filmes em que o roteirista é homem. A vantagem em favor de um filme ser dirigido por uma mulher é 5,3 vezes a de ser dirigido por um homem nos filmes em que a produtora é mulher em relação aos filmes em que o produtor é homem. Verificou-se que para um filme de ficção, com roteirista e produtores homens, a probabilidade do diretor ser também homem é de 99,7\%. Já para um filme de documentário, com roteirista e produtora mulher, a probabilidade da diretora ser mulher é de 93,0\% (ALVES, 2011).

$\mathrm{O}$ resultado da modelagem estatística também apresentou evidências de que a probabilidade da protagonista ser mulher está associada ao sexo do diretor, do roteirista, do fotógrafo, e ao gênero do filme. Estima-se que a vantagem em favor de protagonista mulher em relação à protagonista homem é 120\% maior quando a diretora é mulher do que quando o diretor é homem; e é o dobro quando a roteirista é mulher do que para um roteirista homem. Estima-se também que a vantagem em favor de protagonista mulher em relação à protagonista homem é $150 \%$ maior para filmes de ficção do que para documentários. Conclui-se que a probabilidade da protagonista ser mulher é maior quando as equipes de direção, roteiro e fotografia incluem mulheres (ALVES, 2011). 
Os testes estatísticos confirmam o que teóricos já haviam apontado, que nos filmes dirigidos por mulheres existe uma nova perspectiva: a feminina. $O$ ponto de vista é deslocado para a protagonista mulher. No entanto, é preciso ter cuidado com armadilhas como a de tentar definir características dos filmes dirigidos por mulheres ou encontrar uma definição para o que seria o "olhar feminino".

O gênero não é a única marcação dos corpos, nem dos olhares. É apenas uma delas. Mas outras marcas sociais e suas interações formam o olhar de um/uma cineasta, aliás, de qualquer profissional/pessoa. Cor da pele, raça e etnia, religião, cultura, lugar de nascimento e/ou moradia, nível de escolaridade, desejo e prática sexual, geração, entre outros, juntamente com o gênero. Homens e mulheres se posicionam, agem e reagem, são vistos e significados socialmente, vivenciam suas relações afetivo-sociais-laborais de formas diferentes. Da mesma forma que uma mulher branca se posiciona, reage, é vista e significada socialmente de formas diferentes que uma mulher negra, ou que mulheres de diferentes gerações, mulheres no Brasil e na África, etc.

Ou seja, não é difícil considerar que existem diferenças entre perspectivas femininas e masculinas, o difícil é isolar as diferenças entre os olhares dos cineastas apenas a partir da diferenciação de gênero. Ademais, esperar que seja possível listar uma série de características que descrevam o "cinema de mulheres" é limitar o olhar feminino. Como já dizia Simone de Beauvoir (2008) em o Segundo Sexo, não existe uma mulher, mas várias. Não existe um olhar feminino, existem múltiplos olhares femininos, assim como existem múltiplos olhares masculinos. Precisamos escapar da armadilha de rotular o cinema realizado por mulheres como um gênero cinematográfico. Mulheres realizam filmes de todos os gêneros, sobre todas as temáticas possíveis, a partir de diversas perspectivas, e sob diferentes influências.

\section{Considerações finais}

O cinema tem importante papel na construção e difusão das imagens de homens e mulheres ao longo do tempo, especialmente levando-se em consideração o poder de alcance do cinema hegemônico em quase todo o mundo. Autoras como Joan Scott (1989) e Judith Butler (2003), por exemplo, apontam como pontos fundamentais na conquista da equidade entre homens e mulheres uma mudança na representação da mulher na cultura, na arte e na mídia, e sua inserção igualitária em todos os níveis de hierarquia no mercado de trabalho. A despeito de todas as conquistas das mulheres na educação, na saúde e na vida cultural, as desigualdades entre os sexos ainda persistem em diferentes áreas. As mulheres, de uma forma geral, ainda participam de forma desigual do mercado de trabalho. A divisão sexual das ocupações e a diferença salarial entre os sexos representam os principais desafios ainda a enfrentar na promoção da equidade de gênero neste campo. O cinema tem papel fundamental, seja na retransmissão de antigos e tradicionais valores e distinção de papéis entre os gêneros ou, ao contrário, na transformação desses valores, na desconstrução dos rótulos, na sugestão de novas divisões de funções. Por isso, acreditamos que a entrada da mulher neste campo contribui para a construção de novas representações das mulheres.

Os dados apresentados mostram que a participação das mulheres em funções-chave na produção cinematográfica brasileira e estadunidense, 
especialmente como diretoras e protagonistas, ainda é significativamente menor do que a de homens. Enquanto o cinema prioriza protagonistas homens, estamos reforçando a concentração de poder nas figuras masculinas. Se os homens predominam nos cargos de comando do cinema, as decisões referentes ao planejamento estratégico, seleção de pessoal e execução orçamentária nesta área estão majoritariamente em suas mãos. E, mais importante: a gerência do imaginário, da representação de homens e mulheres e suas relações no trabalho e na família, a disseminação de valores, a representação dos diversos grupos sociais, as escolhas temáticas. Acreditamos que o aumento de mulheres exercendo funções-chave no mercado audiovisual possa impulsionar um aumento de protagonistas mulheres e a possibilidade de novas (e múltiplas) perspectivas no cinema.

\section{Referências}

ALVES, Paula. O cinema brasileiro de 1961 a 2010 sob a perspectiva de gênero. 2011. Escola Nacional de Ciências Estatísticas - ENCE/IBGE, Mestrado em Estudos Populacionais e Pesquisas Sociais, Rio de Janeiro.

BEAUVOIR, Simone. O segundo sexo. Tradução Sérgio Milliet. Rio de Janeiro: Nova Fronteira, 2008.

BUET, J. Films de Femmes: six générations de réalisatrices. Paris: Editions Alternatives, 1999.

BUTLER, J. Problemas de gênero: feminismo e subversão da identidade. Tradução de Renato Aguiar. Rio de Janeiro: Civilização Brasileira, 2003.

. Repensar la vulnerabilidad y la resistencia. $X V$ Simposio de la Asociación Internacional de Fỉósofas (IAPh). Madrid, 24-27 jun. 2014.

DANEY, Serge. "Pour une ciné-démographie". In: DANEY, Serge. Devant la recrudescence des vols de sacs à main. Lyon: Aléas éditeur, 1997.

DARGIS, Manohla. Is There a Real Woman in this Multiplex? In: New York Times, p. 3, mai., 2008.

GUERRILLA GIRLS. Disponível em: <www.guerrillagirls.com> Acesso: 14 mai. 2011.

HIGONNET, Anne. Mujeres, imágenes y representaciones. In: DUBY, Georges; PERROT, Michelle (org). Historia de las mujeres en occidente. Madrid: Taurus Minor, 1993.

KAPLAN, E. Ann. A Mulher e o Cinema: os dois lados da câmera. Rio de Janeiro: Editora Rocco, 1995. 
LAURETIS, Teresa de. Alice doesn't: feminism, semiotics, cinema. Bloomington: Indiana University Press, 1984. 220 p. Technologies of gender: essays on theory, film and fiction. Bloomington: Indiana University Press, 1987.151 p.

LAUZEN, Martha. The Celluloid Ceiling. Center for the Study of Women in Television and Film, San Diego State University. San Diego: 2010.

. The Celluloid Ceiling: Behind the Scenes Employment of Women on the Top 250 Films of 2013. Center for the Study of Women in Television and Film, San Diego State University. San Diego: 2013.

MULVEY, Laura. Prazer visual e cinema narrativo. In: XAVIER, Ismail (org.) $A$ experiência do cinema: antologia. Rio de Janeiro: Edições Graal: Embrafilme, 1983, p. 437-453.

NEVES, Sónia. Chez Duchamp. Porto: MCO Arte Contemporânea, 2007.

OTTONE, G. "Terra Brasil 95-05: el renacimiento del cine brasileño". Festival Internacional de Cine de Las Palmas: Madri, T\&B Editores, 2005.

PESSOA, A. "Por trás das câmeras". In: HOLLANDA, H. Realizadoras de cinema no Brasil: (1930/1988). Rio de Janeiro: CIEC, 1989.

SCOTT, J. Gênero: uma categoria útil para análise histórica. Tradução: Christine R. Dabat e Maria B. Ávila. Nova Iorque: Columbia University Press, 1989.

TREMILLS, K. "Where have all the women gone?" Moving Pictures Magazine: Phoenix, v. 1, n. 3, jan.-fev. 2005.

WILLIAMS, Linda. Screening sex: revelando e dissimulando o sexo". In: Cadernos Pagu, Campinas, n. 38, jan-jun, 2012, p. 13-51.

XAVIER, Ismail. $O$ discurso cinematográfico: a opacidade e a transparência. São Paulo: Paz e Terra, 2008. 212p. 